\title{
Travel blogs on China as a destination image formation agent: A qualitative analysis using Leximancer
}

\begin{abstract}
The Internet spreads tourism information around the world and specifically travel blogs function as an online version of word-of-mouth (eWOM). This research explored the role of blogs as a destination image formation agent for China's inbound tourism. Data were collected from 630 bloggers who wrote on two blog websites about their travels within China in 2011 and 2012. The bloggers on TravelBlog.org and TravelPod.com were mainly from English-speaking countries. Qualitative analysis using Leximancer software was applied and identified nine major textual themes and the relationships among these themes. In order of relative importance, the themes were place, Chinese, people, food, train, city, hotel, China, and students. The research indicated that international tourists tended to have positive images of China.
\end{abstract}

Keywords: destination image formation, travel blogs, China, Leximancer, user-generated content (UGC)

\section{Introduction}

The mobility of culture and tourism has made countries pay greater attention to their nation brands and visitor images. Studies on destination image have proliferated over the past four decades, as scholars have linked perceptions of destinations with visit intentions (Baloglu \& McCleary, 1999). Some of this research has focused on image formation agents, the factors that influence consumers to develop perceptions of particular destinations.

An influential developing country in the Asia-Pacific region because of its economic prowess, China is also gaining prominence both as one of the most important generators of outbound tourism and as a significant global tourism destination. Apart from its unique historic and cultural treasures, China has varied and abundant natural scenery and landscapes. However, among the 400-plus destination image research studies published in English since the 1970s, it is difficult to find many devoted to foreigners' perceptions of China, although this has become a more popular topic since the 2008 Beijing Olympic Games. Recent events have exacerbated the need to more fully comprehend Mainland China's image as an international tourism destination. China has been the recipient of significant recent negative publicity due to air pollution in major cities, disputes with Japan over the ownership 
of islands, China's ambivalence on North Korea, and other political and economic issues. There has also been a softening of inbound tourism to China since 2008 with a decline being experienced in 2013.

To help fill the apparent gap in the research literature, this study evaluated the image of China in how foreign tourists perceive the country as a tourism destination. The specific research objectives were to:

1. Determine the main image themes about China expressed by international tourists in travel blogs.

2. Explore the inter-relationships among concepts expressed within travel blogs.

3. Provide an analysis of overall tourist experiences in China from blog data.

4. Express the academic and practical implications of the research findings on China's destination image through blog analysis.

\section{Literature Review}

\subsection{Destination image and its formation process}

Destination image has been a very popular research topic since the 1970s. Pike (2002, 2007) did a general literature review of destination image, consisting of 142 articles from 1973 to 2000 and 120 articles from 2001 to 2007. Stepchenkova and Mills (2010) provided a meta-analysis of the destination image research literature from 2000-2007 covering 152 articles. Before 2000, studies mainly focused on the perceptions of destination images in North American and European markets; rarely was destination image reviewed in the context of Asian countries. However, studies involving Asian and other countries grew in number from 2001 and 2007. Gallarza, Saura, and Garcia (2002) found that most studies stressed the concept, attributes, formation, measurement and evaluation of tourist destination images. Many of these studies proposed cognitive structures of destination image for individuals or groups of people, and examined how different destination attributes affected attitudes. Several studies focused on the impacts of major events on destination images, with the 2008 Beijing Summer Olympic Games being one example.

In general, destination image research can be divided into three developmental stages since the 1970s. The first stage began when Gunn (1972) proposed the development of destination image into organic, induced, and modified-induced images. This approach was adopted in many subsequent studies (Bonn, 2005; Govers, Go, \& Kumar, 2007; Hosany, Ekinci, \& Uysal, 2006; Kim \& Morrison, 2005). Phelps (1986, page 168) recommended a somewhat different classification of destination 
images as being primary images (actual experiences of a place) and secondary (new visitor) images. Crompton (1979, page 18) offered the classic definition of image "as the sum of beliefs, ideas, and impressions that a person has of a destination." In an exploratory study, he measured the destination image attributes of Mexico. Fakeye and Crompton (1991, page 11) proposed an evolution of destination image from organic to induced and then to a complex image resulting from actual contact with the area. As an extension of Gunn's original concept of destination image, Gartner (1994) suggested the need to consider destination image formation agents (Overt Induced I, Overt Induced II, Covert Induced I, Covert Induced II, Autonomous, Unsolicited Organic, Solicited Organic, and Organic). This first stage of destination image research produced many fundamental definitions and taxonomies of the concept.

The second stage of the academic research on destination image was mainly based on the introduction of attitude theory. Attitude theory became the most common theory used for measurement in destination image studies (Baloglu, 1997; Baloglu \& McCleary, 1999; Beerli \& Martín, 2004; Gartner, 1989; Govers et al., 2007; Hosany et al., 2006; Lee, Lee, \& Lee, 2005; Nadeau, Heslop, O’Reilly, \& Luk, 2008; Pike, 2009; Pike \& Ryan, 2004; Prebensen, 2007; Qu, Kim, \& Im, 2011; Ryan, 2005; San Martín \& Rodríguez del Bosque, 2008; Stepchenkova \& Morrison, 2006, 2008). These researchers concentrated on the cognitive component of image, or the beliefs about destination that Crompton (1979) first articulated in the tourism research literature. Other scholars argued that the affective or emotional component of image was essential in destination evaluation (Baloglu, 1997; Baloglu \& Brinberg, 1997; Baloglu \& McCleary, 1999; Echtner \& Ritchie, 1991; Embacher \& Buttle, 1989). Furthermore, Baloglu and McCleary (1999) described a general framework of destination image formation consisting of perceptual/cognitive, affective, and global/overall components, with the latter resulting from the interaction of cognitive and affective images. Recognizing the importance of cognitive and affective images, these have been frequently analyzed along with information resources, personal factors and socio-demographic characteristics, and motivations (Baloglu \& McCleary, 1999; San Martín \& Rodríguez del Bosque, 2008). Gartner (1994) proposed conative image as the third component, which Pike and Ryan (2004, page 334) described as being analogous to behavior or the intent or action component. The second stage of destination image research was important in the measurement of attitudes and in separating attitudes into distinctive components.

In the third stage, tourism researchers began to give greater recognition and priority to qualitative dimensions of destination image in addition to the quantitative measurement of attitudes. For example, Echtner and Ritchie (1993) used attribute-holistic, functional-psychological and common-unique components to 
interpret the formation of destination image. Many researchers subsequently applied the Echtner and Ritchie model and further developed it to different analysis (Bonn, 2005; Choi, Lehto, \& Morrison, 2007; MacKay \& Couldwell, 2004; O'Leary \& Deegan, 2005; Stepchenkova \& Morrison, 2008). This third stage also involved attempts to connect image with the concepts of destination positioning and branding (Cai, 2002; Pike \& Ryan, 2004; Qu et al., 2011). Qu et al. (2011) proposed that cognitive, affective, and unique images interacted to form the overall or holistic image of a destination.

\subsection{Destination image studies on China}

The first destination image studies in English relating to Mainland China were published in the early 1990s. Gartner and Shen (1992) assessed the impact of the Tiananmen Square incident on China's tourism image. The data were collected before (1989) and after (1990) the event to test U.S. residents' images of China. Almost all of the mean attribute scores declined from 1989 to 1990 showing that the Tiananmen Square incident had a negative impact on China's destination image. The authors concluded that information from autonomous (media) sources had been influential in this image change. Go and Zhang (1997) reviewed the most important attributes of Beijing as an international meeting destination. They concluded that Beijing could increase its competitiveness in the international meeting and exposition market by making improvements in government support, personnel and management, and product and pricing.

There was an upsurge in scholarly interest in China's image surrounding the 2008 Summer Olympic Games in Beijing. Several studies evaluated the impact of the Games on China's country and destination images (Gibson, Qi, \& Zhang, 2008; Green, Lim, Seo, \& Sung, 2010; Heslop, Nadeau, \& O'Reilly, 2010; Li \& Kaplanidou, 2013; Li \& Wang, 2011; Nadeau, O'Reilly, \& Heslop, 2011). Li and Kaplanidou (2013) investigated how the Olympic Games affected tourists' perceptions of China as a tourist destination. U.S. travelers' collective perceptions in terms of destination image and personality did not change significantly from before to after the 2008 Olympic Games. However, this study noted the influence of the media on tourists' destination perceptions, and that media are an important factor in developing destination image and for market segmentation. Pan and Li (2011, page 132) analyzed U.S. residents' destination images of China and found these were dominated by a few very popular phrases, but contained a large amount of phrases in small niches.

Others scholars analyzed the images of specific Chinese destination or attraction images (Qingdao by Ji \& Wall, 2011;Tibet by Mercille, 2005; Zhangjiajie by Son, 
2011; Shanghai by Tang et al., 2012; the Silk Market in Beijing by Wu, Wall, \& Pearce, 2014). Wu et al. (2014) used Leximancer to examine international tourist experiences at the Silk Market based on 149 reviews posted on TripAdvisor.com. Some previous research published in Chinese has analyzed the images of certain cities or particular attractions (including Beijing by Feng, 2011; Nanjing by Huang, Li, \& Gao, 2002; Taishan by Ma, 2011; Xi'an by Song, An, \& Zheng, 2006). There have also been studies about the impacts of famous people on China's tourism and its image (Hunter, 2013; Tang et al., 2009).

Recently more attention has been given to the effects of specific image formation agents on China destination image. Xiao and Mair (2006) analyzed representative narratives about China in English-language newspapers. They found paradoxical images of China in the newspapers, the more positive dimensions being culture/history/arts/religion, attractions/sites/tourist cities, food/lifestyle/recreation/leisure, and rural-urban contrasts (page 8). Li, Pan, Zhang, and Smith (2009) found that the overall and affective images of China improved after U.S. residents were asked to search online for information in planning a one-week trip there. Shani, Chen, Wang, and Hua (2010) evaluated the influence of a promotional video on destination image. China was perceived by the participants as an attractive tourist destination with cultural and ecotourism qualities, but it was also seen as a relatively expensive, hard-to-reach travel destination with safety, social and political issues (page 129). Li and Wang (2011) analyzed Western tourists' perceptions of China's destination image and relevant products through travel blogs, contrasting data before and after the 2008 Olympic Games. They concluded that blog authors had a mixed image of China as a destination and that language was the main constraint for international tourists in China. There are some similarities between the current research and Li and Wang's since both used travel blogs as their databases. However, this analysis was not associated with the Olympic Games and it used a different methodology applied to a much larger sample of blogs. Chen, Hua, \& Wang (2013) administered a questionnaire survey to employees of a major U.S. hospitality company after they had viewed the destination video, China Forever. They concluded that the four salient constructs of the destination image of China were infrastructure and superstructure, culture and nature tourism, hospitality and comfort/security, and perceived value. Environmental, personal, structural, and political constraints would most affect respondents' decisions to travel to China.

There have been studies published in Chinese about international tourists' perceptions of China (e.g., Gao, Ma, \& Wu, 2010). Scholars have also contributed several works on the destination images of Hong Kong and Macau (e.g., Choi, Chan, \& Wu, 1999; Choi et al., 2007; Hsu \& Song, 2013; Leung, Law, \& Lee, 2011; 
McCartney, Butler, \& Bennett, 2008). However, the selected focus of this research was on relevant articles published in English on Mainland China.

Despite the recent upward trend, there are still many different research perspectives yet to be explored on international tourists' destination images of China. This is especially true with respect to information obtained online through the Internet and social media channels.

\subsection{Internet information and user-generated content (UGC)}

Studies on the influence of word-of-mouth (WOM) communications have existed for many decades (Brown \& Reingen, 1987; Richins, 1983). WOM may represent a set of data that helps organizations understand why customers are and are not satisfied. Litvin, Goldsmith, and Pan (2008, page 461) proposed the general concept of eWOM (electronic word-of-mouth) as "all informal communications directed at consumers through Internet-based technology related to the usage or characteristics of particular goods and services, or their sellers." Increasing Internet use has resulted in virtual interactions among consumers and with the suppliers of tourism services and experiences. Through features including social network services (SNS) and travel review sites, the Internet is becoming an increasingly influential venue for communications and knowledge exchange. This is having a powerful impact on the choice of tourism products, destination images, and travel intentions.

Simpson and Siguaw (2008) defined WOM as product- or service-related verbal, person-to-person communication (Arndt, 1967; Wangenheim, 2005). They explored the effects of satisfaction and identity salience (place attachment part of the self-construct) on WOM communications in a comparative study of visitor and resident groups in a region of Texas. Their study indicated that satisfaction and identity salience were important in predicting people's willingness to communicate positive WOM about the destination, and the willingness levels varied by tourist and resident type. Zhang, Ye, Law, and Li (2010) found that consumer-generated ratings of hospitality services and products were positively related to online popularity of restaurants. They suggested that since Internet communications emphasize intangible experiences, they are important in generating WOM and eWOM in tourism and hospitality.

Schmalleger and Carson (2008) identified different types of travel blogs including consumer to consumer (C2C), business to business (B2B), business to consumer (B2C) and government to consumer $(\mathrm{G} 2 \mathrm{C})$. These all are important for tourism and destination marketing and have five key functions: promotion, product distribution, communication, management, and research. Internet-based communications makes 
blogs easy to update, flexible in structure, and allows anonymous interaction among people. Mack, Blose, and Pan (2008, page 141) examined the credibility of blogs versus traditional WOM. They found that although personal blogs $(\mathrm{C} 2 \mathrm{C})$ were more credible than commercial blogs (B2C and G2C); they were nowhere near as credible as traditional word of mouth.

Pan, MacLaurin, and Crotts (2007, page 25) suggested that travel blogs were an inexpensive means to gather rich, authentic, and unsolicited customer feedback about visitor experiences in destinations. Blogs can help managers and marketers better understand tourists' attitudes toward destinations (Carson, 2008; Li \& Wang, 2011; Wenger, 2008). Customer reviews posted on websites such as TripAdvisor.com are also being used to mine attitudes and opinions on tourism destinations and specific attractions (Cong et al., 2014; Wu et al., 2014)

Online markets are increasingly being driven by user-generated content (UGC). UGC can be analyzed through online video platforms such as YouTube (Cha, Kwak, Rodriguez, Ahn, \& Moon, 2007) and by digital footprinting of photos and mobile phone messages (Girardin, Blat, Calabrese, Fiore, \& Ratti, 2008). Daugherty, Eastin, and Bright (2010) proposed that consumers' willingness to experience UGC depends on their attitudes toward the consumption or the creation of UGC. Ye, Law, Gu, and Chen (2011) identified the impact of online user-generated reviews on business performance by using data extracted from a major online travel agency in China. The results showed that traveler reviews had a significant impact on online sales, highlighting the importance of online user-generated reviews to tourism business performance. Akehurst (2009) examined the development of UGC in the use of blogs and concluded that blogs were perceived to be more credible and trustworthy than traditional marketing communications. Burgess, Sellitto, Cox, and Buultjens (2009) also found out that online travel consumers considered UGC as a supportive tool for their travel decisions.

Blogs are potentially important sources for people in forming destination images and as references for making travel decisions. With China becoming one of the most popular destinations in the world, travel blogs written by foreigners could be significant as an image formation agent about China.

\section{Research Method}

\subsection{Information source and data collection}

This study evaluated how international visitors perceived China as a tourist destination. The top two travel blog websites were identified as being 
http://www.TravelBlog.org and http://www.TravelPod.com. These two websites have more submissions than other travel blog websites and were used as the data source for this research. TravelPod.com also has a directory of blogs about destinations based on continents, countries, states and cities. English is the language most applied in travel blogs and used for major software programs. Therefore, this research was based on travel blog entries written in English and specifically about travel activities in Mainland China in 2011 to 2012. In these two websites, all visitors and bloggers have free access for reading or creating blogs by posting text, photos, and multimedia files. Furthermore, comments can be left by readers beneath the blogs.

All blogs posted from January $1^{\text {st }}, 2011$ to December $31^{\text {st }}, 2012$ were downloaded. As each author could post more than one blog, multiple blogs for some authors were collected. The final database consisted of posts from 630 bloggers in total. Moreover, TravelPod.com gathers the nationalities from authors and this was also recorded for further analysis. There were 335 bloggers in 2011, 264 bloggers in 2012, and 31 bloggers that wrote from 2011 to 2012, crossing the two years. Some 471 bloggers were from TravelBlog.org and 159 from TravelPod.com (Table 1). The valid blog entries were saved by bloggers' names (or IDs in the websites) with titles and dates in separate Microsoft .docx files. Later all the .docx files were transferred into .txt files for Leximancer analysis.

\section{[Insert Table 1 about here]}

\subsection{Data analysis}

The data collected from travel blogs were qualitatively analyzed by Leximancer software. Leximancer is different from other content analysis software. Unlike NVivo, ATLAS.ti, and CATPAC, Leximancer does not apply word frequency, or coding of terms and phrases. Leximancer, working with its own algorithms, is used for analyzing the meanings within passages of text by extracting the main concepts and ideas. It applies a quantitative method to conduct qualitative analysis by using different algorithms for stages (Indulska, Hovorka, \& Recker, 2011) and is mostly used to study psychology and human language (Cretchley, Rooney, \& Gallois, 2010; Smith \& Humphreys, 2006), qualitative health research (Cretchley, Gallois, Chenery, $\&$ Smith, 2010), and literature reviews for defining different concepts (Dann, 2010; Indulska et al., 2011). It has also been applied in tourism and hospitality research, for example to identify event images in newspaper reports (Scott \& Smith, 2005), to assess hotel accommodation manager perceptions of disability service provision (Darcy \& Pegg, 2011), and to analyze tourist shopping experiences in Beijing Silk 
Market (Wu et al., 2014). In this study, Leximancer software was applied to analyze large and long qualitative data in order to identify the main concepts from textual data. Visual concept maps and statistical outputs were generated that assisted in gaining greater insights and comprehension of language (Wu et al., 2014).

Several technical operations were required to obtain interpretable results: (1) certain words such as "I'm", "the", "of", "on" and other meaningless words were identified and removed while processing text; (2) a custom configuration and editing concept seed and thesaurus were set up for semantic information; (3) repeated steps of examining the results, exploring and modifying settings, then further discovering the main topics within the text; and (4) relevant concepts were put together as a theme, and their relationships highlighted.

\section{Findings}

Many of the blogs were written as travel diaries documenting the 630 writers' activities in China. The total number of words in the text database was 135,925 for 2011 to 2012. Figure 1 shows the concept map that was the foundation for exploring the underlying text.

[Insert Figure 1 about here]

The nine main themes and their connectivity rates (in parentheses) were place (100\%), Chinese (90\%), people (77\%), food (72\%), train (63\%), city (61\%), hotel (38\%), China (22\%), and students (11\%) in order of relative importance. These also were the main themes representing international tourists' travel experiences in China. The connectivity rate percentages from Leximancer (2013) calculated the connectedness of concepts within the themes and reflected the importance of each theme.

\subsection{Overall experience in traveling within China}

The nine themes are considered to be the most influential aspects affecting international tourists' destination images of China. Figure 1 shows the themes and their associated concepts. In the Leximancer output, the smaller grey nodes are the concepts and these are grouped with different rainbow-colored themes. The most important theme - place in this research - is assigned the color red, and then in descending order of importance the remaining themes are identified by orange, yellow, green, blue and purple. Eighty-one concepts were identified by Leximancer. The more 
the concepts placed within a theme, the richer the meaning the theme expresses.

An initial interpretation of Figure 1 might suggest that it reflects most of the basic necessities for travel in a foreign country including accommodations, food and beverages, transportation, attraction and sites, local communities, and activities and entertainment. The themes with stronger connections to several concepts were place, Chinese, people, food, and city. By contrast, students and China had few related concepts. China might be considered as an overall and united impression rather than a fragmented destination image, making it form as an individual theme. The students theme was rather interesting to detect and it is explained in greater detail later.

\subsubsection{Place as the most important theme}

Place was the most important theme in the blog narrations of international tourists in China. Figure 2 shows how Leximancer quantified and displayed the conceptual structure of the place theme. Most of the place theme concepts were connected to attractions, sites, or destinations. Place was particularly strongly connected with the word ancient.

\section{[Insert Figure 2 about here]}

The relationship between place and ancient is displayed in Figure 3. Leximancer software indicated this was the strongest pathway between concepts. The knowledge pathway was from place leading to old and then to ancient. These pathways tell stories from the text and focus on the indirect connections among concepts.

[Insert Figure 3 about here]

Place was a way for international tourists to express their thoughts and impressions of the sites or attractions they visited in China. Typical examples mentioning place were:

Like Yarkand, Hotan was famous as a strategic junction on the old Silk Road particularly in the Han and Tang dynasties, with routes through to India, Tibet, Central Asia and far west China.

The Three Lesser Gorges area is an unusually beautiful and natural place, where amazing rock-walls echo of ancient history. 
The most popular attractions in this research were associated with the words wall and temple. Wall represented the Great Wall, one of the most recognized World Heritage Sites in China with its spectacular scenery and one-of-a-kind architectural construction. It represents the wisdom of ancient knowledge and the history of development progress. A previous study by Pan and Li (2011) of U.S. residents' images of China indicated that $85 \%$ of the respondents cited either Beijing or the Great Wall when asked to name China's distinctive tourist attractions. Temple is iconic for the traditional religions of Daoism and Buddhism in China, and along with them the folklore of local lifestyles and moral heritage. In a holistic way, place meant somewhere ancient that is able to represent Chinese culture and history. It was notable that there were less concepts relating to the natural resources of China. Even if the blogs from international tourists mentioned natural resources, such as in the example above, the text still reflected impressions of ancient history.

\subsubsection{Cross-cultural image perception - China, Chinese, and people}

China was a major theme and Figure 4 displays which concepts international tourists linked with the country's name. These included the images of the country, culture, history, travel destinations, and experiences. China and Chinese had certain similarities.

[Insert Figure 4 about here]

Chinese was the second strongest theme in this research. The usage of Chinese covered aspects of the environment or conditions in China (people, food, etc.) and the Chinese language. The concept map for Chinese is shown in Figure 5. The related concepts with Chinese included politics, culture, people, food, and study. This theme contained information on how writers experienced different aspects of their travels in China. The strong connection between Chinese and government reflected how international tourists felt in experiencing China through many perspectives. The following comment from one blog was typical of these types of observations:

Additionally, we learned that although it doesn't look like it (because of all of the economic activity), the communist government is still very much involved in all of this activity with more than 50\% of the Chinese economy coming from state owned enterprises. 
People as a concept was also strongly connected to government when associated with the theme Chinese. The knowledge pathway for these concepts is depicted in Figure 6. The pathway went from people to Chinese, and then led to English, young, fact, and government. The reflections in the blogs from travel experiences tended to emphasize differences in either culture or politics, with the following two quotes serving as good examples:

The Chinese government and the Chinese people seem to be highly organized as a whole. They are an extremely hard working, conforming people who want to see their country succeed

I have been speaking to plenty of Chinese people lately and they are very eager to share their hopes, lives and dreams with a foreigner, which allows me a good insight in their culture and situation.

[Insert Figure 6 about here]

Cultural experiences also included language communication and development. Typically, the words Chinese and English were used together when language barriers were encountered. The following blog quote describes a language challenge that those who cannot read Chinese can experience in some parts of China:

The first thing that immediately struck me as I left the bus station was the lack of English anywhere. Usually you can find the word "hotel" at least somewhere, but not here.

Language problems are one of the obstacles in traveling within China and constrain cross-cultural interaction (Li \& Wang, 2011). These problems could be addressed with more multilingual signs and better communications at tourist destinations and attractions.

\subsubsection{Cross-cultural experiences of taste-food}

Transportation is one of the most important enablers of travel. Trains, buses, and stations are mainly used in inter-city journeys and buses for traveling within cities. They normally function as nodes and carriers that connect different places while 
traveling, but they can also be attractions for tourists. Most importantly, stations and air terminals offer the first impressions for tourists and leave certain images of cities. Hotels, hostels, and restaurants are indispensable for tourists and their frequent mentions in these blogs further underlines their importance to destinations. Positive and negative attitudes towards transportation, accommodation, and food and beverage services could be among the most influential factors for destination images. Having Western food choices readily available in addition to having great experiences with Chinese food appeared to be very important to bloggers.

There is even a KFC and Starbucks (I think) done up in traditional Chinese style.

Served in a traditional Chinese banquet style we were inundated with numerous dishes that made our taste buds dance. If only every meal could be this good.

Villages, local, and markets were important concepts reflecting traditional culture and lifestyles. In some blogs, these concepts were closely connected to traditional food:

There were a lot more local tribal people and ethnic minorities, and the handicraft shops reflected this. The food was awesome too - we tried the local Tibetan style bread stuffed with yak meat and had to go back the next day to have it again!

Food is a complicated concept and has a richer meaning than just consuming dishes. Food not only satisfies tourists' physiological requirements, but it also represents many different traditional Chinese cultural styles. With a mixture of many ethnic groups, Chinese culture offers many different local foods and performances that promote the specialty of each group. This is not only a way of gaining more income, but also is the sharing of culture and may give tourists a greater sense of authenticity. Markets also convey a similar experience since gazing upon groups of local people while going about their usual lives is sometimes the difference that many tourists seek to experience. The combination of places like markets and restaurants with food can effectively express the culture of China and fulfill tourists' desired experiences. 


\subsubsection{Contradictions between old and new - city}

City was the third most important theme in this research. Li and Wang (2011) suggested that cities are major destinations, connectors or stopovers for international tourists in China. They are important travel hubs for tourists and instrumental in creating first impressions. Figure 1 shows only one concept to describe city and that was ancient. The bloggers tended to use ancient to describe cities and to demonstrate their culture or history in certain ways. Many writers focused on the legacy of Chinese culture and history, and explored the old relics:

There actually is walled old city but it has been demolished and is being rebuilt at the moment. So we did not see any of the city centre or old town and we only focused on the ancient Buddhist sites.

Beijing and Shanghai were the only two cities frequently mentioned by the bloggers from among the 600 cities in China. In a cultural context, Beijing was the most discussed city, followed by Shanghai. Beijing and Shanghai are the most international and busiest cities in China, and possess the largest transportation hubs and networks. They also have abundant culture which is a combination of both ancient and modern. This mixture leads to discussions of contradictions between old and new in China's major cities. The following are two examples of the interest in these comparisons:

I have gotten to understand a very important country in the world during a time of high growth, seeing how its people and infrastructure are growing nicely to put it on the world stage. I have seen the "old" China by riding through farmland and small rural communities as well as the "new" China evidenced by Guangzhou, Beijing and Shanghai. I've met a range of people and am impressed with how the younger generation is tackling the future, wanting to become more "modern"....

Beijing is a fantastic sprawling city, full of ancient architecture and attitudes, yet also showcases its up and coming modern side.

The blending of thousands of years of history with the most modern technologies and architecture - often in one sightline - displays a fascinating mixture of time periods that can be uniquely experienced in China. This seems to be one of the most indelible images received by several bloggers when traveling in China. 


\subsubsection{Culture experience in language barriers - students}

As mentioned earlier, it was interesting that students and school were frequently found in this database. Partly this was due to blogs by foreigners who were teaching English in China. Other bloggers were expatriates and exchange students traveling around China during school breaks for more than three months. These longer-stay tourists tended to have more in-depth experiences with China and better understood the language and communication issues, as demonstrated in the following quotes:

It's been interesting that the students from our school are markedly more advanced in their spoken English than the students from other schools. They're all comfortable with the foreign teachers.

English is compulsory from Grade 3 Primary School through to completion of Senior High School. Students from small rural schools are noted for having far less English instruction than city schools.

We stayed at a hostel filled with all sorts of international kids; German, Polish, Dutch, French, Spanish, English, and Swiss. Most were exchange students traveling during the break from school.

The longer that international tourists stay in China, the more they tend to know about how the government works and what the government policies are. Moreover, they have a fuller comprehension of the situation for the Chinese people and the English language. The requirement of language learning has attracted many foreigners to China to teach English. These English teachers when traveling around China may understand China differently from those who stay in China for the short-term and this should become a focus for future studies.

\subsection{Image on satisfaction of traveling in China}

Leximancer identified 8,045 favorable and 2,087 unfavorable terms while running the program and these are shown in Figure 7 . There were approximately four times more positive responses than negative, indicating that the bloggers tended to have favorable impressions of their travel experiences in China. However, there were still many negative impressions including the following examples:

Unfortunately behavior also changed crossing the border. Loud noises and 
continuous spitting are just some of these rather negative Chinese behavioral threats. And loud spiting is not only limited to old guys. You should have seen our faces when we turned around to see who had just made that disgusting sound, to discover a beautiful lady as the origin of the noise.

The only negative of this place was the thin timber walls and floors let ALL the noise through. Anyone talking or walking around and you hear them distinctly.

The bloggers complained about the sanitary behaviors of Chinese people and their loudness when talking. Although the negative impressions did not feature in the most frequently used words; they certainly require some thought and attention, especially since they have also been noted in outbound Chinese tourist behaviors. Spitting and loud noises uttered in public places can be unacceptable and disturbing to people from other countries that prefer to preserve the cleanliness and comfort of their environments. Leaving politics and cultural issues behind, the environments in destinations should be maintained by everyone in order to create favorable images that trigger positive WOM and intentions to revisit.

[Insert Figure 7 about here]

\subsection{Geographical analysis on TravelPod.com}

Geographic origin information is difficult to obtain, especially for blog data as sometimes the information posted is anonymous. Blogs from TravelPod.com provided nationality information from international bloggers which is shown in Table 2 . Although Table 2 only includes the nationality information from TravelPod.com, it is still useful in displaying the geographical distribution of the international travelers in China. The 159 international bloggers were distributed among 16 countries. The top five countries mainly use English as the official language (U.S., U.K., Australia, Canada, and New Zealand) and their bloggers contributed $89 \%$ of the posts. English speaking countries tended to be the majority of international bloggers since the retrieved blogs were written in English. There were still many blogs written in other languages which were not included in this research's database.

[Insert Table 2 about here]

Previous research by Volo (2010) assessed the value of blogs as tourist experiences and their influence on the travel intentions of prospective tourists. The 
results showed that the way tourists use blogs differed by cultural background. The blogs written in Italian were adjudged to have more potential to influence the decision-making processes of prospective visitors than the English blogs since their comments often contained recommendations and authors' declarations of their own future intentions to travel to the subject destination. However, all the data for this research were blogs written in English and may not be representative of blogs written in other languages and for non-English cultures. The results represent a preliminary exploration of China's destination image and need to be supplemented further in the future.

\section{Conclusions and implications}

\subsection{Academic implications}

Academically, this research helps to fill a gap in the English-language research due to a lack of destination image studies with a focus on Mainland China. The concepts detected by Leximancer influence international tourists' images of Mainland China and can be considered as explanatory variables in image formation. The overall image formation of China is influenced by its settings (natural/man-made), government (politics and policies), culture and history (including ancient relics, people and food), and built facilities (accommodation and transportation). The differences in people's travel experiences in China were attributed to nine themes each associated with certain concepts. It could be argued that image formation for bloggers themselves is dynamic, continuously changing and being modified while traveling. Blogs may be way of showing whether images are being supported or modified, if the blogs are being written onsite in China. However, to the contrary Gartner (1994, page 205) stated that the larger the entity, the more slowly images change, and undoubtedly Mainland China would be classified as a very large destination country. It seems prudent, therefore, to separate the images of the writers (bloggers) from the readers of their posts.

The application of Leximancer provided a more comprehensive picture of the destination images of Mainland China by supplying both visual diagrams and charts along with lexical concepts. These outputs are different from other content analysis programs which just present word frequencies and connections. The visual results from Leximancer clearly display the analysis of blog texts and make it easier to trace back to important lexical concepts. In this research, the heritage and cultural elements were the most influential on the international bloggers who traveled within China. Many of the themes contained the concepts of history, ancient, and cultural 
expression and these were found when tracing back to the original blog texts.

Beijing and Shanghai were the most frequently used concepts among cities in China for several reasons. As the capital city/government center and business/financial hub of China, these two cities are the most strategic transportation wise. The juxtapositioning of ancient relics and structures along with the most modern architecture and latest digital technologies are also distinct characteristics of both Shanghai and Beijing. From this research, the combination of old and new appears to influence travelers' images of Mainland China, and Beijing and Shanghai are two of the best venues to have these experiences. The pervasive history and cultural heritage not only passes on knowledge of ancient China, but also is reflected in a rich inheritance of traditions and lifestyles. While the heritage and cultural aspects were predominant in this research, China's abundant natural resources did not attain a high priority as might be expected. Although China's natural scenery is unique and often spectacular, it appears to be overshadowed by the thousands of years of culture and history of the nation.

The findings of this research tend to support those of other researchers (e.g., Gao, Ma, \& Wu, 2010; Li \& Wang, 2011; Son, 2011; ) with respect to travelers' positive and negative experiences in Mainland China. Both studies determined that language and interpersonal communication barriers were significant for foreigners traveling in China. Language is a bridge that facilitates greater cross-cultural interaction and understanding; therefore it is vitally important while traveling to other countries. In contrast to other emerging tourism destinations worldwide, China seems to be underperforming in facilitating greater understanding of sites and environments through the use of English and other major foreign languages. This may partly be a result of an overreliance on the booming domestic tourism market. Moreover, English and Chinese had close connections with other themes and concepts in this research, further demonstrating that English has to be given a higher priority in this contemporary era of China's tourism development. Overall, the paradoxical images of China noted in previous studies (Chen, Hua, \& Wang, 2013; Li \& Wang, 2011; Xiao $\&$ Mair, 2006) were also evidenced in this research.

\subsection{Practical implications}

It has been suggested that Mainland China will become one of the world's top international tourism destinations in the future. This will, of course, be dependent on inbound tourism flows to China and these will be influenced by how the country is marketed and developed to cater to international tourists. Although this research was exploratory in nature, it has some practical implications for China's international 
tourism development and marketing.

Positive comments on experiences with travel in China were far more frequent than negative ones. Nevertheless, there were negative remarks that should not be overlooked such as spitting or loudness while talking in public places. The Chinese Government is aware of these issues with the public behavior of some of its citizens and has already issued guidelines on better etiquette. There is always potential for misunderstandings and clashes when people of distinctly different cultures interact and these situations are exacerbated by the overcrowding that occurs at major tourism attractions and public spaces in China. The management of these places in China definitely needs to pay greater attention to these issues and find solutions that improve the experiences of all tourists.

From the tourism development perspective, significant improvements are needed in verbal communications and in various forms of signage to enable more comfortable and enjoyable experiences in China. Being more "international tourist friendly" also should involve more interpretation in multiple languages at popular attractions and sites. For pre-trip planning, all destination and attraction information should be easily available on multilingual websites from the tourism offices of every province, city, and major tourism attraction. Particular attention needs to be paid to bus, train and air terminals, and to the design of hotels and hostels, since these are often the sources of most important first impressions.

The international destination marketing and branding of China should be informed by some of the results of this research. The current emphasis on promoting the slogan of Beautiful China seems inconsistent with these bloggers' emphasis on the heritage and culture of China, rather than its natural resources. Moreover the recent negative international publicity about the high levels of air pollution in major Chinese cities also suggests that references to the natural environment should be avoided as they will not ring true for foreign audiences. This research suggests that emphasizing the image of China as an ancient place will be much closer to the actual images in the marketplace.

\subsection{Limitations}

One of the major limitations of this research was that the blogs were all written in English and the results therefore do not reflect the worldwide image of Mainland China as a tourism destination. The nationalities of the bloggers were not evenly distributed and the thoughts from five countries dominated the findings. Applying only one method in doing this research tended to narrow the scope of the results and their interpretation. Applying other quantitative and qualitative research methods 
could have led to a deeper understanding of the themes and concepts revealed through the Leximancer analysis.

Although inferred from previous studies, this research has not proven that the blogs of travelers to Mainland China influence potential visitors or that this information is seen as being more credible than traditional marketing sources. Additionally, it has been acknowledged that the text within blogs may have differing impacts on writers and readers.

This study analyzed online users' opinions from travel blogs (in English only) that they wrote and uploaded; arguably these bloggers represent only a relatively small proportion of all international tourists to Mainland China. Moreover, blogs are just one information source, and there are many other online and offline reviews and comments on travel within Mainland China. Therefore, this study's results may not reflect the perspectives of a wider cross-section of international tourists to Mainland China.

\subsection{Recommendations for future research}

This research was exploratory with the goal of producing a better understanding of the concepts that matter the most to international tourists in forming images of Mainland China. It was not a specific research objective to focus on the potential influence of negative impressions on overall images, but future studies should address this topic.

More research is certainly needed to further clarify the destination and country images of Mainland China. The boundaries between country image and destination image were unclear from this research. In fact, the results represent a mixture of images of China as a nation and of China as a tourism destination. Other research methods need to be applied such as questionnaire surveys with foreign tourists in China and potential visitors to China. These further studies will diversify the range of available data and provide comparisons among different country-of-origin and cultural groups. These comparisons are especially needed between short-haul (Korea and Japan) and long-haul (North America and Europe) international markets. There is also a future need to determine if there are significant differences among visitors to Mainland China according to their lengths of stay in the country. 


\section{References}

Akehurst, G. (2009). User generated content: the use of blogs for tourism organizations and tourism consumers. Service Business, 3(1), 51-61.

Arndt, J. (1967). The role of product-related conversation in the diffusion of a new product. Journal of Marketing Research, 1(4), 291-95.

Baloglu, S. (1997). The relationship between destination images and socio demographic and trip characteristics of international travellers. Journal of Vacation Marketing, 3(3), 221-233.

Baloglu, S., \& Brinberg, D. (1997). Affective images of tourism destinations. Journal of Travel Research, 35(4), 11-15.

Baloglu, S., \& McCleary, K. W. (1999). A model of destination image formation. Annals of Tourism Research, 26(4), 868-897.

Beerli, A., \& Martín, J. D. (2004). Factors influencing destination image. Annals of Tourism Research, 31(3), 657-681.

Bonn, M. A. (2005). International versus domestic visitors: an examination of destination image perceptions. Journal of Travel Research, 43(3), 294-301.

Brown, J. J., \& Reingen, P. H. (1987). Social ties and word-of-mouth Rreferral behavior. Journal of Consumer Research, 14(3), 350-362.

Burgess, S., Sellitto, C., Cox, C., \& Buultjens, J. (2009). User-generated content (UGC) in tourism: Benefits and concerns of online consumers. Paper presented at the 17th European Conference on Information Systems.

Cai, L. A. (2002). Cooperative branding for rural destinations. Annals of Tourism Research, 29(3), 720-742.

Carson, D. (2008). The 'blogosphere' as a market research tool for tourism destinations: a case study of Australia's Northern Territory. Journal of Vacation Marketing, 14(2), 111-119.

Cha, M., Kwak, H., Rodriguez, P., Ahn, Y., \& Moon, S. (2007). I Tube, You Tube, Everybody Tubes: analyzing the world's largest user generated content video system. Paper presented at the Computers in Human Behavior.

Chen, P. J., Hua, N., \& Wang, Y. (2013). Mediating perceived travel constraints: the role of destination image. Journal of Travel \& Tourism Marketing, 30(3), 201-221.

Choi, W. M., Chan, A., \& Wu, J. (1999). A qualitative and quantitative assessment of Hong Kong's image as a tourist destination. Tourism Management, 20(3), 361-365.

Choi, S., Lehto, X. Y., \& Morrison, A. M. (2007). Destination image representation on the web: Content analysis of Macau travel related websites. Tourism 
Management, 28(1), 118-129.

Cong, L., Wu, B., Morrison, A. M., Shu, H., \& Wang, M. (2014). Analysis of wildlife tourism experiences with endangered species: an exploratory study of encounters with giant pandas in Chengdu, China. Tourism Management, 40, 300-310.

Cretchley, J., Gallois, C., Chenery, H., \& Smith, A. (2010). Conversations between carers and people with Schizophrenia: a qualitative analysis using Leximancer. Qualitative Health Research, 20(12), 1611-1628.

Cretchley, J., Rooney, D., \& Gallois, C. (2010). Mapping in a 40-year history with Leximancer: themes and concepts in the Journal of Cross-Cultural Psychology. Journal of Cross-Cultural Psychology, 41, 318-328.

Crompton, J. L. (1979). An assessment of the image of Mexico as a vacation destination and the influence of geographical location upon that image. Journal of Travel Research, 17(4), 18-23.

Dann, S. (2010). Redefining social marketing with contemporary commercial marketing definitions. Journal of Business Research, 63(2), 147-153.

Darcy, S., \& Pegg, S. (2011). Towards strategic intent: perceptions of disability service provision amongst hotel accommodation managers. International Journal of Hospitality Management, 30(2), 468-476.

Daugherty, T., Eastin, M. S, \& Bright, L. (2010). Exploring consumer motivations for creating user-generated content. American Academy of Advertising, 8(2), 16-25.

Echtner, C. M., \& Ritchie, J. R. B. (1991). The meaning and measurement of destination image. Journal of Tourism Studies, 2(2), 2-12.

Echtner, C. M., \& Ritchie, J. R. B. (1993). The measurement of destination image: An empirical assessment. Journal of Travel Research, 31(4), 3-13.

Embacher, J., \& Buttle, F. (1989). A repertory grid analysis of Austria's image as a summer vacation destination. Journal of Travel Research, 27(3), 3-7.

Fakeye, P. C., \& Crompton, J. L. (1991). Image differences between prospective, first-time, and repeat visitors to the Lower Rio Grande Valley. Journal of Travel Research, 30(2), 10-16.

Feng, J. (2011). Perceptions of the image of Beijing's tourist destinatons - An analysis of multi-dimensional discourses on the blogs from Chinese and Western tourists. Tourism Tribune, 26(9), 19-28. (in Chinese)

Gallarza, M. G., Saura, I. G., \& Garcia, H. C. (2002). Destination image - towards a conceptual framework. Annals of Tourism Research, 29(1), 56-78. 
Gao, J., Ma, Y., \& Wu, B. (2010). Defects of China's inbound tourism from foreign tourists' perspective: an analysis based on grounded theory research paradigm. Tourism Science, 24(5), 49-55.

Gartner, W. C. (1989). Tourism image: attribute measurement of state tourism products ssing multidimensional scaling techniques. Journal of Travel Research, 28(2), 16-20.

Gartner, W. C. (1994). Image formation process. Journal of Travel \& Tourism Marketing, 2(2/3), 191-216.

Gartner, W. C., \& Shen, J. (1992). The impact of Tiananmen Square on China's tourism image. Journal of Travel Research, 30(4), 47-52.

Gibson, H. J., Qi, C. X., \& Zhang, J. J. (2008). Destination image and intent to visit China and the 2008 Beijing Olympic Games. Journal of Sport Management, 22(4), 427-450.

Girardin, F., Blat, J., Calabrese, F., Fiore, F. D., \& Ratti, C. (2008). Digital footprinting: uncovering tourists with user-generated content. Pervasive Computing, 7(4), 36-43.

Go, F., \& Zhang, W. (1997). Applying importance-performance analysis to Beijing as an internataional meeting destination. Journal of Travel Research, 35(4), 42-49.

Govers, R., Go, F. M., \& Kumar, K. (2007). Virtual destination image a new measurement approach. Annals of Tourism Research, 34(4), 977-997.

Green, C., Lim, S. Y., Seo, W. J., \& Sung, Y. (2010). Effects of cultural exposure through pre-event media. Journal of Sport \& Tourism, 15(1), 89-102.

Gunn, C. (1972). Vacationscape. Designing Tourist Regions. Washington DC: Taylor and Francis.

Heslop, L. A., Nadeau, J., \& O'Reilly, N. (2010). China and the Olympics: views of insiders and outsiders. International Marketing Review, 27(4), 404-433.

Hosany, S., Ekinci, Y., \& Uysal, M. (2006). Destination image and destination personality: An application of branding theories to tourism places. Journal of Business Research, 59(5), 638-642.

Hsu, C. H. C., \& Song, H. (2013). Destination image in travel magazines: a textual pictorial analysis of Hong Kong and Macau. Journal of Vacation Marketing, 19(3), 253-268.

Huang, Z., Li, X., \& Gao, Y. (2002). Measurement and analysis on tourism destination image - Taking Nanjing as a study case. Nankai Business Review, 3, 69-73. (in Chinese)

Hunter, W. C. (2013). China's Chairman Mao: A visual analysis of Hunan Province online destination image. Tourism Management, 34, 101-111. 
Indulska, M., Hovorka, D., \& Recker, J. (2011). Quantitative approached to content analysis: identifying conceptual drift across publication outlets. European Journal of Information Systems, 21(2), 49-69.

Ji, S., \& Wall, G. (2011). Visitor and resident images of Qingdao, China, as a tourism destination. Journal of China Tourism Research, 7(2), 207-228.

Kim, S. S., \& Morrison, A. M. (2005). Change of images of South Korea among foreign tourists after the 2002 FIFA World Cup. Tourism Management, 26(2), 233-247.

Lee, C., Lee, Y., \& Lee, B. (2005). Korea's destination image formed by the 2002 World Cup. Annals of Tourism Research, 32(4), 839-858.

Leung, D., Law, R., \& Lee, H. A. (2011). The perceived destination image of Hong Kong on Ctrip.com. International Journal of Tourism Research, 13(2), 124.140.

Leximancer. (2013). Leximancer FAQ. Retrieved 27th, November, 2013, from http://hypermancer.leximancer.com/faq/index.html

Li, X., \& Kaplanidou, K. (2013). The impact of the 2008 Beijing Olympic Games on China's destination brand: a U.S.-based examination. Journal of Hospitality \& Tourism Research, 37(2), 237-261.

Li, X., Pan, B., Zhang, L., and Smith, W. W. (2009). The effect of online information search on image development: insights from a mixed-methods study. Journal of Travel Research, 48(1), 45-57.

Li, X., \& Wang, Y. (2011). China in the eyes of Western travelers as represented in travel blogs. Journal of Travel \& Tourism Marketing, 28(7), 689-719.

Litvin, S. W., Goldsmith, R. E., \& Pan, B. (2008). Electronic word-of-mouth in hospitality and tourism management. Tourism Management, 29(3), 458-468.

McCartney, G., Butler, R., \& Bennett, M. (2008). A strategic use of the communication mix in the destination image-formation process. Journal of Travel Research, 47(2), 183-196.

Ma, M. (2011). A research on the effects of familiarity index on tourism destination image: A case study of Mount Taishan. Tourism Science, 25(2) 30-38. (in Chinese)

Mack, R. W., Blose, J. E., \& Pan, B. (2008). Believe it or not: Credibility of blogs in tourism. Journal of Vacation Marketing, 14(2), 133-144.

MacKay, K. J., \& Couldwell, C. M. (2004). Using visitor-employed photography to investigate destination image. Journal of Travel Research, 42(4), 390-396.

Mercille, J. (2005). Media effects on image. Annals of Tourism Research, 32(4), 1039-1055.

Nadeau, J., Heslop, L., O’Reilly, N., \& Luk, P. (2008). Destination in a country image context. Annals of Tourism Research, 35(1), 84-106. 
Nadeau, J., O'Reilly, N, \& Heslop. (2011). China's Olympic destination: tourist evaluations of China and the Games. International Journal of Culture, Tourism and Hospitality Research, 5(3), 235-246.

O'Leary, S., \& Deegan, J. (2005). Ireland's image as a tourism destination in France: attribute importance and performance. Journal of Travel Research, 43(3), 247-256.

Pan, B., MacLaurin, T., \& Crotts, J. (2007). Travel blogs and the implications for destination marketing. Journal of Travel Research, 46(1), 35-45.

Pan, B., \& Li, X. (2011). The long tail of destination image and online marketing. Annals of Tourism Research, 38(1), 132-152.

Phelps, A. (1986). Holiday destination image - The problem of assessment: An example developed in Menorca. Tourism Management, 7(3), 168-180.

Pike, S. (2002). Destination image analysis-a review of 142 papers from 1973-2000. Tourism Management, 23(5), 541-549.

Pike, S. (2007). Destination image literature - 2001 to 2007. ACTA Touristica, 19(2), 101-228.

Pike, S. (2009). Destination brand positions of a competitive set of near-home destinations. Tourism Management, 30(6), 857-866.

Pike, S., \& Ryan, C. (2004). Destination positioning analysis through a comparison cognitive, affective and conative perceptions. Journal of Travel Research, 42(4), 333-342.

Prebensen, N. K. (2007). Exploring tourists' images of a distant destination. Tourism Management, 28(3), 747-756.

Qu, H., Kim, L., \& Im, H. (2011). A model of destination branding: Integrating the concepts of the branding and destination image. Tourism Management, 32(3), 465-476.

Richins, M. L. (1983). Negative word-of-mouth by dissatisfied consumers: A pilot study. Journal of Marketing, 47(1), 68-78.

Ryan, C. (2005). Structuring destination image: Aaqualitative approach. Journal of Travel Research, 44(2), 143-150.

San Martín, H., \& Rodríguez del Bosque, I. A. (2008). Exploring the cognitiveaffective nature of destination image and the role of psychological factors in its formation. Tourism Management, 29(2), 263-277.

Schmalleger, D., \& Carson, D. (2008). Blogs in tourism: changing approaches to information exchange. Journal of Vacation Marketing, 14(2), 99-110.

Scott, N., \& Smith, A. (2005). Use of automated content analysis techniques for event image assessment. Tourism Recreation Research, 30(2), 87-91.

Shani, A., Chen, P., Wang, Y., \& Hua, N. (2010). Testing the impact of a promotional 
video on destination image change: application of China as a tourism destination. International Journal of Tourism Research, 12(2), 116-133.

Simpson, P. M., \& Siguaw, J. A. (2008). Destination word of mouth: the role of traveler type, residents, and identity salience. Journal of Travel Research, 47(2), 167-182.

Smith, A. E., \& Humphreys, M. S. (2006). Evaluation of unsupervised semantic mapping of natural language with Leximancer concept mapping. Behavior Research Methods, 38(2), 262-279.

Son, A. (2011). International tourists' image of Zhangjiajie, China: content analysis of travel blogs. International Journal of Culture, Tourism and Hospitality Research, 5(3), 306-315.

Song, Z., An, Y., \& Zheng, P. (2006). An IPA analysis of tourism destination image A case study of Xi'an residents' perception on the tourism destination image of Hainan, China. Tourism Tribune, 21(10), 26-32. (in Chinese)

Stepchenkova, S., \& Morrison, A. M. (2006). The destination image of Russia: from the online induced perspective. Tourism Management, 27(5), 943-956.

Stepchenkova, S., \& Morrison, A. M. (2008). Russia's destination image among American pleasure travelers: revisiting Echtner and Ritchie. Tourism Management, 29(3), 548-560.

Stepchenkova, S., \& Mills, J. E. (2010). Destination image: a meta-analysis of 20002007 research. Journal of Hospitality Marketing \& Management, 19(6), 575-609.

Tang, L., Morrison, A. M., Lehto, X. Y., Kline, S. F., \& Pearce, P. L. (2009). Effectiveness criteria for icons as tourist attractions: A comparative study between the United States and China. Journal of Travel \& Tourism Marketing, 26(3), 284-302.

Tang, L., Manthiou, A., Morrison, A. M., Shin, J. Y., \& Chiang, L. (2012). A holistic approach to activity preference patterns: international tourists and their visits to Shanghai, China. International Journal of Tourism Sciences, 12(1), 107-136.

Volo, S. (2010). Bloggers' reported tourist experiences: Their utility as a tourism data source and their effect on prospective tourists. Journal of Vacation Marketing, 16(4), 297-311.

Wangenheim, F. V. (2005). Postswitching negative word of mouth. Journal of Service Research, 8(1), 67-78.

Wenger, A. (2008). Analysis of travel bloggers' characteristics and their communication about Austria as a tourism destination. Journal of Vacation Marketing, 14(2), 169-176. 
Wu, M. Y., Wall, G., \& Pearce, P. L. (2014). Shopping experiences: International tourists in Beijing's Silk Market. Tourism Management, 41, 96-106.

Xiao, H., \& Mair, H. L. (2006). "A paradox of images": representation of China as a tourist destination. Journal of Travel \& Tourism Marketing, 20(2), 1-14.

Ye, Q., Law, R., Gu, B., \& Chen, W. (2011). The influence of user-generated content on traveler behavior: an empirical investigation on the effects of e-word-of-mouth to hotel online bookings. Computers in Human Behavior, 27(2), 634-639.

Zhang, Z., Ye, Q., Law, R., \& Li, Y. (2010). The impact of e-word-of-mouth on the online popularity of restaurants: A comparison of consumer reviews and editor reviews. International Journal of Hospitality Management, 29(4), 694-700. 